EPiC Series in Computing
Volume 63, 2019, Pages 211-220
Proceedings of 32nd International Conference on
Computer Applications in Industry and Engineering

\title{
An Online Community Site that Incorporates the use of Social Networks Software: A Case of an Open University in Thailand
}

\author{
Thitima Srivatanakul \\ York College - City University of New York, U.S.A. \\ tsrivatanakul@york.cuny.edu
}

\begin{abstract}
In the digital period, a large part of our daily activities revolves around social networks software. Social networks software, such as Facebook and Twitter, have brought new opportunities for users to create online communities, share content and opinions on the online platforms. Today's colleges and universities have also employed the power of social media to increase students' interaction and engagement. This is particularly useful for online or distance learners, where face-to-face communication is limited. This paper aims to determine requirements for an online community site that incorporates the use of social networks software. The requirements were gathered from stakeholders at an open university in Thailand. The study proposes the desired characteristics and functional requirements of an online community site in a distance learning context.
\end{abstract}

\section{Introduction}

For the past decades, the web 2.0 and online social media platforms, or commonly known as 'social networks software' or 'social networks services' or SNS have brought about a major transformation on how individuals interact and communicate. SNS bounds individuals with common interests together, forming online communities. The use of one or more SNSs, e.g. Facebook, Twitter and Instagram, has now become daily practice for many of us. SNSs are commonly used by individuals to communicate with friends and family, share information ideas and personal opinions. In business, SNS is used to promote products, services and provide a digital presence for the brands. Education institutions have also leveraged the power of SNS to increase students' learning experience and engagement.

According to Moongela and McNeill [1], SNSs are used by students for both social and academic purposes. Their findings reported that, based on students' perception, social media has a positive influence on their academic engagement. Connolly [2] indicated that SNSs have played a nontrivial role 
in educational settings and can also provide educational benefits. Distance and online learning in highereducation also enjoy the rapid growth of SNS. An initial survey by the author of this paper found that $80 \%$ of the top 20 open universities worldwide as ranked by Webometrics [3] have an official Facebook fan page. As argued by Roblyer et al. [4], a more effective learning environment in distance education can be created through the use of an SNS by promoting social interactions between the instructors and the students and among the students themselves.

Clearly, there are advantages of using social media platforms in educational settings. However, in reality, SNSs are more commonly used as a social tool rather than an educational one [4] and that they have not been realized to its fullest extent. Survey result by Vidal et al. [5] pointed out that although university students believed that SNS would offer education benefit, none have used any SNS for education experience at the instruction of teaching staff. Forkosh-Baruch and Hershkovitz [6] identified the activity pattern, content patterns and interactivity of social media accounts of higher education institutes in Israel. Their work concluded that social media accounts as employed by universities are not being used much as means of strengthening ties to the community and that there is an increasing need for research on their utilization.

Another challenge faced by institutions is that there exist numerous different social accounts created by different academic departments and supporting offices. The aim of this research is to propose an online community site that incorporate the use of SNSs in order to promote social interactions with and among students. The study attempts to leverage the use of SNSs to strengthen community ties. A case study from an open university in Thailand is presented here in this paper. Sukhothai Thammathirat Open University (STOU) is an open university in Thailand that utilizes a distance teaching/learning system. From the perspectives of its stakeholders which include the administrations, faculty members, supporting staff, current students and alumni, an online community site was developed based on their views and requirements. The main contribution of this paper is to summarize the main characteristics and functional requirements necessary for the development of an online community in a distance educational setting. This is of particular useful since in distance learning education face-to-face communication is limited.

The organization of the remainder of the paper is as follows. The next section provides the background topics that are related to this study. The subsequent sections outline the research motivation and objectives, research methodology, discussion and the results of the study. The last section concludes the paper and provides directions for future work.

\section{Background}

\subsection{Social Networks Software}

The advent of Web 2.0 technologies has transformed how people use the web, moving from consumers to creators of digital contents. Web 2.0 applications including blogs, wiki and social network sites (e.g. Facebook, Twitter, LinkedIn) emphasize more on interactive participation of users over simple content delivery [7]. One unique feature of an SNS that differentiates it from other Web 2.0 applications is that it allows individuals to connect with one another, forming networks of friends. Users of an SNS are able to communicate, interact and collaborate with one another. As formally defined by Boyd and Ellison [8], SNSs are "web-based services that allow individuals to (1) construct a public or semi-public profile within a bounded system, (2) articulate a list of other users with whom they share a connection, and (3) view and traverse their list of connections and those made by others within the system.".

The design intent, however, for each SNS somewhat differs. LinkedIn focuses on business and professional networking, whereas Facebook was designed to connect family and friends. Instagram 
An Online Community Site that Incorporates the use of Social Networks Software: ... T. Srivatanakul

focuses on visual content while Twitter focuses more on short messages. Nevertheless, they possess common characteristics. Medaglia et al. [9] categorized common characteristics of SNSs as follows:

1. Digital Persona/Virtual Identity - users of SNSs are able to develop an online persona, or the representation of the users.

2. Network Building - users of SNSs are able to search for friends, connect with new people and build contacts with shared interests.

3. Network Maintenance - users of SNSs are able to reach their networks over time, e.g. post notification of friends and update of status through feeds.

4. Network Interaction - users of SNSs are able to interact with one another, e.g. through comments, shared activities and exchange of virtual objects.

5. User Generation of Virtual Content - users of SNSs are able to post texts, images, video or other virtual contents.

6. Network Self-Governance-SNS must possess acceptable norms and codes of behavior within the network. For example, users can report inappropriate contents.

Popular SNSs like Facebook, Twitter, LinkedIn, Instagram all possess the above characteristics [9]. For example, the 'tagging picture' feature on Facebook and 'location-based search engine' on Twitter help with network building, while 'status update' on Facebook and 'Email alerts' on Twitter help with network maintenance [9]. SNS is a powerful platform that enables the people of the world to be more connected. According to a study by Brandtzaeg and Heim [10], the top three motivational reasons for an individual to use SNSs are 1) to get in contact with new people, 2) to keep in touch with their friends and 3) to socialize in general. Next section, we will see the use of SNS in higher education.

\subsection{SNS and Higher Education}

The growth of SNSs use is apparent in higher education. With the ever-increasing number of SNSs users, universities and colleges have started presenting themselves in SNSs . Almost all (96\%) of the top 50 universities worldwide as ranked by Webometrics advertised at least one SNS on their official websites. The current adoption of SNSs at universities can be seen at various levels. At the university level, SNSs are often used for delivery of university's news, upcoming events and useful academic resources. Another common use by the university is to promote itself to prospective students and for marketing and public relations purposes. At a departmental level, the contents tend to be more focused around on academic and social activities for current students. At a course-level, the SNSs are used for collaborative working among students.

Moreover, a number of research work has been conducted in order to understand how SNSs is used by universities and to understand its effect towards learning performances. Rothkrantz [11] discussed some successful applications of SNSs use to the teaching-learning process. The sample applications were 1) to get students to analyze data available on Facebook as part of a group project, 2) to assign students to collaborate with other students to accomplish some given tasks, 3) to present daily academic experiences and activities of students. Work by Eid and Al-Jabri [12] indicated that knowledge sharing is a strong predictor of students learning performance and that the use of SNSs for enjoyment and entertainment can benefit student's communication and comprehension skills. Work by Liccardi et al. [13] concluded that the use of social media in universities can help students with their learning experiences and that social media can be used as a pedagogical agent. 
Researchers also investigated the effect of social media on student engagement. However, little research exists on how SNSs use is linked to student engagement in relation to academic performance. Early work in this area suggested that the time spent on Facebook is related to students' involvement on campus [14]. However, a more recent study by Junco [15] concluded that the time spent in certain Facebook activities can be positively predictive or negatively predictive of engagement depending on the outcome variable. For example, time spent on Facebook is positively predictive of time spent in cocurricular activities while checking up with friends were negatively predictive of student engagement [15]. Dyson et al. [16] also reported that the use of Facebook group to delivery of course materials to students did not yield higher self-reported engagement score than those without access to the platform. According to Junco et al. [17], faculty play an important role to achieve effective results in outcomes for students' collaboration and engagement.

\subsection{Online Communities}

A community is a group of people with common interests. Universities are communities of faculty members, supporting staff, current students and alumni bound by learning. With computer systems facilitating the communication and interactions between different group members, an online or virtual community can be formed [18]. There are various views on how online communities are defined. For instance, Porter [19] characterized virtual (online) communities around 'shared interests', whereas Wellman [20] gave emphasis on 'social belonging and identity' aspects of the online communities.

This work adopted a definition of an 'online community' defined by Rotman and Preece [21] as follows:

Online community is "a group (or various subgroups) of people, brought together by a shared interest, using a virtual platform, to interact and create user-generated content that is accessible to all community members, while cultivating communal culture and adhering to specific norms."

An online community, according to the above definition, in an education setting can be formed with the use of SNS e.g. Facebook, YouTube, Twitter where students, faculty members, supporting staff or even alumni share interests, create content and interact with one another. The following section discusses one approach in building an online community. A case study of STOU is presented here.

\section{Research Motivation and Objectives of the study}

Sukhothai Thammathirat Open University (STOU) is an open university in Thailand that utilizes a distance teaching/learning system. The main teaching materials include textbooks and workbooks mailed to students. Supplementary learning includes delivering of lectures via television and radio programs. Students study at their own pace according to their conditions and locations [22]. As in any other distance learning setting, interactions between student and faculty and among students themselves are limited.

To facilitate interactions and communications among different stakeholders at STOU, an online platform where students can share their interests, actively participate in university's events, interact and connect with fellow students is desired. STOU is already using various SNSs to reach its audience. However, one of the challenges is that there exist numerous social accounts maintained by different academic departments, supporting offices and individuals. Some is created officially and approved by the university and some is not. An online community site that incorporates several of these SNSs seems to be one possible approach to facilitate students to connect and stay engaged with the university and the faculty.

The objective of the study is to conduct a requirements analysis for an online community site for STOU. The stakeholders of the system were the administrations, faculty members, supporting staff, current students and alumni. The study proposed the following research questions:

- What are the desired characteristics of the online community site for STOU? 
An Online Community Site that Incorporates the use of Social Networks Software: ... T. Srivatanakul

- What are the desired functional requirements of the online community site for STOU?

Requirements were elicited through both quantitative and qualitative data collection methods. Based on the result of the analysis, an online community site was developed, and evaluation of its usefulness is discussed.

\section{Research Methodology}

The study used both quantitative and qualitative methodologies. A questionnaire which utilized a five-point Likert scale addressed the participants' opinion on 1) the desired characteristics of the online community site and 2) the desired functional requirements of the online community site. Demographic information and social media usage profile were also collected from the questionnaire. To assess the content validity of the questionnaire, three experts in the field were chosen to evaluate the consistency of the content and confirm it was valid for the purpose of the study. The index of Item-Objective Congruence (IOC) was employed to carry out the screening of questions specifically selecting items with IOC higher than 0.5 . The questionnaire was also initially tested by 30 participants each from both the student and faculty group, the reliability (Cronbach's alpha was 0.95 ) was suitable.

Participants in the quantitative component of this study were the university's faculty members, supporting staff, current students and alumni. Stratified random sampling was used to obtain a representative sample, considering each academic department as a stratum, with a confidence level of $95 \%$ and an estimation error of 5\%. A self-administered questionnaire was distributed to the participants. In summary, there were 90 participants from faculty ( 25 male, 65 female), 334 participants from supporting staff (106 male, 228 female), 505 participants from current students (216 male, 288 female, $1 \mathrm{~N} / \mathrm{A}$ ), and 552 participants from alumni (222 male, 329 female, $1 \mathrm{~N} / \mathrm{A}$ ).

The qualitative data for this study were also gathered through semi-structured interviews held with the administrations (16 participants) and additional focus groups with the participating faculty members (12 participants) and supporting staff (16 participants). The qualitative research focused on two main areas. First, the participants were asked about their opinions on the benefits of building a community website that harnessed the power of SNSs. Second, the participants were asked about the desired characteristics and functional requirements of the online community site.

\section{Results from Requirements Analysis}

Through the result from the requirement elicitation process using both quantitative and qualitative methodologies, the research questions can be answered as follows.

\subsection{What are the desired characteristics of an online community site?}

1. Two-way communication must be supported - At the time of the study, phone communication $(74.3 \%)$ was the most commonly used method for students to contact the university. This type of communication is used predominantly for two-way communication. Digital platforms (e.g. live chat and emails) were not used extensively by the students. Less than half of the current students $(32.7 \%)$ and alumni (31.7\%) stated that they have ever used email to contact their professors and supporting staff. Based on the interview and focus group sessions, many believe that fostering two-way communication in the online environment can help encourage students to be involved and stay connected. This is as opposed to students playing just the receiver part in a one-way communication (e.g. university's website). The online community site should therefore support and facilitate various 
forms of online two-way communication among different stakeholders. Different forms of two-way communication include answering of students' questions, discussing of a topic with shared interests, showing interests in some events (by clicking 'likes') and sharing of contents within your networks.

2. Strengthening the social presence of the 'official' social accounts - One of the challenges identified during the interviews and focus group process was that there are a number of social accounts or pages that were not created by the university or authorized bodies. These pages look like official pages but instead run by individuals such as students or alumni. These pages maybe mistakenly identified as channels that speak on behalf of the university, academic departments and offices. Therefore, based on the survey data, there is a need for students to be able to distinguish official channels from 'unofficial' channels. University's approved or official channels managed by faculty and staff must be made publicly available for students to easily find and search for them.

3. Accommodating diverse interests - STOU comprises of many constituent groups with different interests and goals. The diversity is reflected in the demographic part of the survey. The age of participants from the current students group ranges from 21 year-old or below to 61 year-old or above, with most participants (60.4\%) aged between 26-40 years. Most participants (91.8\%) from the current students group were employed during their time of study. Their occupations varied from working for the government and private sectors to farmers and laborers. Based on the voices from the administrations and faculty members, the contents produced by the university's social media channels should accommodate different interests and goals of the users as well. Users should also have the ability to set the preferences on the specific contents that they would like to see and be able to filter out posts that are irrelevant to them.

4. Promoting social engagement and networking - Students at STOU are distance learners. The characteristics of distance learners are different from students in the traditional classroom environment. They are self-motivated, self-directed and independent individuals. Overcoming the feeling of isolation is often a challenge in a distance learning environment. However, based on the findings of the survey, the majority of the students (62.8\%) agreed and strongly agreed that social media platforms can help to promote a social engagement among students, faculty and community members. $73.7 \%$ of the students agreed and strongly agreed that SNSs can help to improve communication among students, the faculty members and the supporting staff. The administrations and faculty members also believed that social engagement and networking would be possible with the use of a more targeted contents and the availability of an online platform in which the users can easily and effectively build connections with one other.

\subsection{What are the desired functional requirements of the online community site for STOU?}

Functional requirements depict the behaviors of the software system. The desired characteristics discussed above were realized into functional requirements. Additional functional requirements were derived through the iterative development model of software development. They can be summarized as follows:

1. View integrated social media posts - The system shall display SNS posts to users by integrating the posts from different sources onto the site. Only posts from valid and specific social accounts will get displayed on the site. This means that only university's official social accounts can be selected. By integrating various posts from different SNSs, this can give the users a good sense of what is going on in the community. Figure 1 shows an example of how posts from both Facebook and Twitter are displayed on the online community site. 


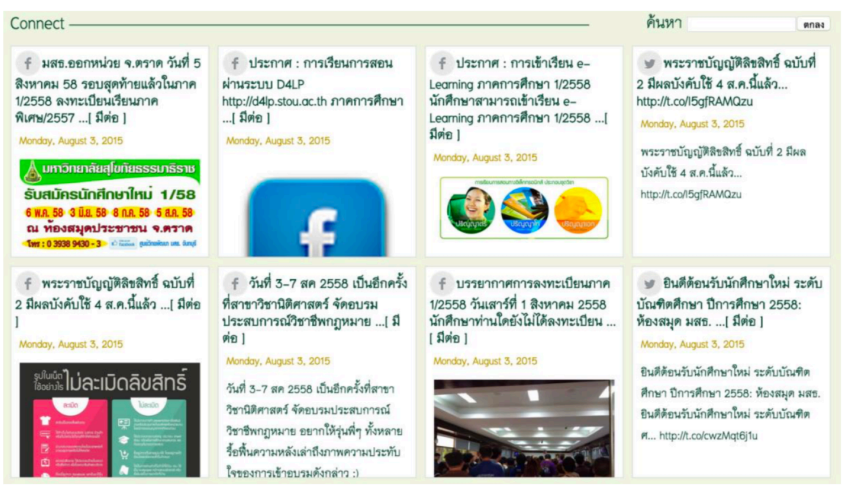

Figure 1: Integrated posts from various social accounts

2. Search and filter of posts - The system shall display posts that are relevant to the users. Typically, users are usually interested in contents from one or more social media channels but not all of them. For example, a student from Computer Science department would be interested in viewing posts from both the department, its school and the university. Therefore, with the filter and search features, users would be able to view and search for the topics of interest in an efficient manner.

3. Find university's official social accounts - Different departments and supporting offices in the university have their own social accounts in different SNSs. Many of our stakeholders stated that it is important for students to be able to identify which accounts are official and which is not. Therefore, the site shall be able to list all the accounts for different academic departments, supporting offices, student clubs and associations. For example, if the user is from the Computer Science Department, he/she would be able to know which social accounts belong to the department and be able to connect to them.

4. View hashtaged posts and hashtag campaigns - Hashtag campaigns can create brand awareness and increase the visibility of the content. For example, \#STOUGraduation hashtag can be used during the annual graduation ceremony. Such a campaign can help get students involved and to promote the event more successfully. Therefore, the online community site shall be able to display all the posts that use the hashtags as specified to draw more attention to the users. The posts can be from any users whose posts are set as public. Users can browse posts from any users from the SNSs that use the assigned hashtags. University can also advertise the active hashtag campaigns on the website.

5. Back-end Functionalities - The system shall support various back-end functionalities such as 1) to manage (add/delete/update) the different social accounts for different departments and organization units, 2) to unpublish or remove any inappropriate posts from the site if needed, 3) to advertise hashtag campaigns and 4) to view the number of posts from different departments and organization units.

\subsection{Evaluation of the Online Community Site}

Once requirements were gathered and analyzed, the system was developed using an iterative development model. The system was then evaluated by 44 participants based on user satisfaction on its user interface design and its features. $77.28 \%$ of the participants said there were highly satisfied and satisfied with the overall user interface design. $90.91 \%$ of the participants stated that there were highly satisfied and satisfied that social accounts are integrated into one virtual environment and $84.1 \%$ of the participants were highly satisfied and satisfied with the search and filter features that enable them to focus on the topics/posts of interest. 


\section{Discussion}

This research set out to analyze requirements for an online community site. Incorporating the use of the most popular SNSs identified from the study, an online community site was developed and evaluated. The use of SNSs were incorporated into the online community site because of their popularity among the students. The study found that $84.8 \%$ of students are already using at least one of the social media platforms as part of their daily routine. Facebook was the most popular SNS among students. Moreover, the study also showed that only $1 \%$ of the students has never accessed an SNS. This indicated that most students are already familiar with the technology. Work by Akbari et al. [23] also supported that both teachers and students are willing to accept the use of online social networks in education settings. However, only $19.7 \%$ of students stated that they use one of the SNSs to communicate with their professors or staff. This is probably because there was no formal policy on the use of SNSs to support academic activities. The use of SNSs was at the discretion of the faculty.

Through this study, the administrations have shown support in the use of SNSs in education setting and that an online community site that incorporate the use of SNSs should be able to help increase students' interactions among themselves and with the faculty and staff. The study attempts to answer two questions. First, we are interested to know the desired characteristics of an online community site. In summary, the online community site, in the distance learning system context, should facilitate twoway communication and strengthen the university's social presence, while accommodating diverse interests of the students and promoting social engagement and networking of students. Second, we are interested in understanding the functional requirements of the online community site itself. One critical requirement identified is that it should facilitate the viewing, searching and filtering of contents fed by different social accounts. The Application Programming Interface (APIs) provided by the SNSs made it possible for the online community site to integrate posts from various social accounts and platforms. The concept is known as "mash-up" in computer science [24]. Although the concept is not new, the work however shows what are the key considerations when implementing one.

\section{Conclusion}

The paper presents one approach in utilizing the use of SNSs to good effect. This study analyzes the requirements for an online community site that incorporates the use of SNSs from perspectives of various stakeholders at an open university in Thailand. The main contribution of this work is to propose the desired characteristics and functional requirements of an online community site for a distance learning environment. For future work, the comparison of students' engagement between those who use and do not use the online community site can be conducted. This is to understand whether or not the online community site would be positive predictive to student engagement.

\subsection{Acknowledgement}

This research was funded by Institute of Research and Development, Sukhothai Thammathirat Open University, Nonthaburi, Thailand. I therefore would like to take this opportunity to thank them. 
An Online Community Site that Incorporates the use of Social Networks Software: ... T. Srivatanakul

\section{References}

[1] H. Moongela and J. McNeill, "Perceptions of social media on students' academic engagement in tertiary education," in Proceedings of the South African Institute of Computer Scientists and Information Technologists - SAICSIT'17, Thaba Nchu, South Africa, 2017.

[2] M. Connolly, "Benefits and Drawbacks of Social Media in Education," 2011. [Online]. Available: https://wcer.wisc.edu/news/detail/benefits-and-drawbacks-of-social-media-ineducation. [Accessed June 2019].

[3] Webometrics, "Ranking Web of Universities," [Online]. Available: http://www.webometrics.info/en. [Accessed May 2019].

[4] M. Roblyer, M. McDaniel, M. Webb, J. Herman and J. Witty, "Findings on Facebook in higher education: A comparison of college faculty and student uses and perceptions of social networking sites.," The Internet and higher education, vol. 13, no. 3, pp. 134-140, 2010.

[5] C. E. Vidal, J. G. Martínez, M. L. Fortuño and M. G. Cervera, "University students' attitudes towards and expectations of the educational use of social networks.," RUSC, Universities and Knowledge Society Journal, vol. 8, no. 1, pp. 186-199, 2011.

[6] A. Forkosh-Baruch and A. Hershkovitz, "A case study of Israeli higher-education institutes sharing scholarly information with the community via social networks.," The Internet and Higher Education, vol. 15, no. 1, pp. 58-68, 2012.

[7] T. O'Reilly, What Is Web 2.0, O'Reilly Media, Inc., 2009.

[8] D. Boyd and N. Ellison, "Social Network Sites: Definition, history and scholarship," Journal of Computer-mediated Communication, vol. 13, no. 1, pp. 210-230, 2007.

[9] R. Medaglia, J. Rose, T. Nyvang and Ø. Sæbø, "Characteristics of Social Networking Services," in MCIS, 2009.

[10] P. B. Brandtzæg and J. Heim, "Why people use social networking sites," in International conference on online communities and social computing, Springer, Berlin, Heidelberg, 2009.

[11] L. Rothkrantz, "On the Use of Social Media in Distance Learning.," in Proceedings of the 17th International Conference on Computer Systems and Technologies - ComSysTech'16, 2016.

[12] M. I. Eid and I. M. Al-Jabri, "Social networking, knowledge sharing, and student learning: The case of university students," Computers and Education, vol. 99, pp. 14-27, 2016.

[13] I. Liccardi, A. Ounnas, R. Pau, E. Massey, P. Kinnunen, S. Lewthwaite, M. Midy and C. Sarkar, "The role of social networks in students' learning experiences," ACM Sigcse Bulletin, vol. 39, no. 4, pp. 224-237, 2007.

[14] G. Heiberger and R. Harper, "Have you Facebooked Astin lately? Using technology to increase student involvement," In R. Junco, \& D. M. Timm (Eds.), Using emerging technologies to enhance student engagement. New Directions for Student Services, no. 124, pp. 19-35, 2008.

[15] R. Junco, "The relationship between frequency of Facebook use, participation in Facebook activities, and student engagement.," Computers and Education, vol. 58, no. 1, pp. 162-171, 2012.

[16] B. Dyson, K. Vickers, J. Turtle, S. Cowan and A. Tassone, "Evaluating the use of Facebook to increase student engagement and understanding in lecture-based classes.," Higher Education, vol. 62, no. 2, pp. 303-313, 2015. 
An Online Community Site that Incorporates the use of Social Networks Software: ... T. Srivatanakul

[17] R. Junco, C. M. Elavsky and G. Heiberger, "Putting twitter to the test: Assessing outcomes for student collaboration, engagement and success," British Journal of Educational Technology, vol. 44, no. 2, pp. 273-287.

[18] J. Preece, Online Communities - Designing Usability, Supporting Sociability, John Wiley and Sons Ltd, 2000.

[19] C. Porter, "A typology of virtual communities: a multi-disciplinary foundation for future research," Journal of Computer-Mediated Communication, vol. 10, 2004.

[20] B. Wellman, "Physical place and cyberplace: the rise of personalized networking', International Journal of Urban and Regional Research," International Journal of Urban and Regional Research, vol. 25, pp. 227-252.

[21] D. Rotman and J. Preece, "The 'WeTube' in YouTube - creating an online community through video sharing," International Journal Web Based Communities, vol. 6, no. 3, pp. 317$333,2010$.

[22] STOU, "STOU Distance Learning System," [Online]. Available: https://www.stou.ac.th/main/en/distance.html. [Accessed June 2019].

[23] E. Akbari, A. Naderi, M. H. Yazdi, R. J. Simons and A. Pilot, "Attitude of Teachers and Students towards formal Learning through Online Social Networks.," Journal of Interactive Learning Research, vol. 27, no. 2, pp. 101-123, 2016.

[24] J. Yu, B. Benatallah, F. Casati and F. \& Daniel, "Understanding mashup development," IEEE Internet Computing, vol. 12, no. 5, pp. 44-52, 2008. 